\title{
Molecular basis of allergen cross-reactivity: Non-specific lipid transfer proteins from wheat flour and peach fruit as models
}

\author{
Leticia Tordesillas , Luis F. Pacios , Arancha Palacin , Santiago Quirce ,Alicia Armentia , \\ Domingo Barber , Gabriel Salcedo , Araceli Diaz-Perales \\ Unidad de Bioquímica, Departamento de Biotecnología, E.TS. ingenieros Agónomos, UPM, Cizdad Universitaria, 28040 Madrid, Spain \\ unidad de Ouimica y Bioquimica, Departamento de Biotecnologia, E.TS. Ingenteros de Montes, UPM, Madrid, Spain \\ Servicio de Alergia, Hospital universitario La Paz, Madrid, Spain \\ Sección de Aleryia, Hospltai Universitario Rio Horteya, Valiadolid, Spain \\ Departamento de $1+D$, ALK-Abello, Madrid, Spain
}

Kenwords:

Non-specitic lipid transter protein

Pru p 3

Trì 14

Cross-reactivity

IgE epitopes

Mimotopes

Electrostatic potential

\begin{abstract}
A B S T R A C T
Peach non-specific lipid transfer protein (Pru p 3; nslTP) has been characterized as the major food allergen in the adult Mediterranean population. Its wheat homologous protein, Tri a 14 has a relevant inhalant allergen in occupational baker's asthma. Different sensitization patterns to these allergens have been found in patients with this latter disorder. The objective of the present study was to characterize IgE epitopes of Tri a 14 and to compare them with those of Pru p 3 using three complementary strategies: the analysis of lgE-binding capacity of decapeptides bound to membrane, the identification of mimotopes using a phage display random peptide library, and the analysis of the surface electrostatic potential of both allergens. Thus, synthetic overlapping decapeptides, covering the Pru p 3 and Tri a 14 amino acid sequences, were used to identify sequential regions involved in recognition of $\operatorname{lgE}$ from baker's asthma patients sensitized to both nsLTPs. A phage display library was screened with total IgE from the same patients, and positive clones sequentially selected using the purified allergens, allowed to identify mimotopes (conformational epitopes) of Tri a 14 and Pru p 3. Both sequential regions and mimotopes were localized in the corresponding 3D molecular surface and their electrostatic properties were analyzed. Common sequential regions with strong [gE-binding capacity ( residues 31-40and 71-80) were identified in Tri a 14 and Pru p 3, whereas regions Tri a 14,1-60 and Pru p 311-20 were found specific of each allergen. A major conformational epitope (mimotope), L34H35N36R39S40S42D43G74V75L77P78Y79T80, which comprised the two common sequential epitopes, was located ìn Trì a 14, and a very similar one in Pru p 3. However, differences were detected on the surface electrostatic potential of both mimotopes: a first part (around residues 31-45) showed similar positive features in both allergens, whereas a second part (around residues 74-80) was markedly negative in Tri a 14 but neutral-positive in Pru p 3.Trì a 14 and Pru p 3 have a similar confommational region involved in lgE-binding, although their electrostatic features are different. Additionally, common and specific sequential IgE-binding regions were mapped in both allergens. These findings could be instrumental in understanding the cross-reactivity and specificity of sensitization to both homologous allergens.
\end{abstract}

\section{Introduction}

Non-specific lipid transfer proteins (nsLTPs), particularly peach Pru p 3, are the most important plant food allergens in the Mediter- ranean area (Asero et al.. 2009; Fernandez-Rivas et al., 2003; Salcedo et al., 2007; van Ree, 2002). They constitute a panallergen family of $9 \mathrm{kDa}$ ( $90-95$ amino acids) basic peptides, with a rigid 3Dstructure due to the presence of four conserved disulphide bridges (Salcedo et al., 2007), nsLTPs have been considered as true food allergens, being primary sensitizers by the oral route, and proposed as plant food allergen model (Salcedo et al., 2007; van Ree, 2002). However, an increasing body of experimental data point out to a complementary role as inhalant allergens, linked in some cases to plant food and pollen cross-reactions (Barber et al., 2008; Lauer et al. 2007: Zuidmeer and van Ree, 2007). In this context, wheat LTP Tri a 14 has been recently identified as a relevant allergen involved 
both in wheat food allergy and baker's asthma (Palacin et al., 2007. 2009; Pastorello et al., 2007).

Baker's asthma is one of the most frequent occupational diseases, affecting around 1-10\% of bakery workers (Brant, 2007; jacobs et al., 2008). The inhalation of wheat flour is the most common cause, although some additives, such as fungal $\alpha$-amylases, have also been described as allergens eliciting baker's asthma (Brant, 2007: Tatham and Shewry, 2008). Several wheat protein families, mainly from the salt-soluble fraction (albumins plus globulins), and particularly those belonging to the $\alpha$-amylase inhibitor family, have been associated with this disorder (Armentia et al., 1993; Tatham and Shewry, 2008). However, no proper panel of molecular tools (purified allergens) has been still developed for this allergy. A wheat LTP, named Tri a 14 , has been proposed as a potential useful diagnostic tool, based on its high sensitization rate $(60 \%$ of sera with specific lgE to the allergen) and in vivo (SPT) positive response (62\% of tested patients) (Palacin et al., 2007, 2009). Furthermore, a complex sensitization profile to Tri a 14 and peach Pru p 3 have been described in baker's asthma patients (Palacin et al., 2007, 2009), indicating that there are high or poor cross-reactivity between the two allergens (i.e, recognition of mainly common and specific lgE (B)-epitopes) depending of the analyzed patient.

lgE epitopes have mainly been studied by lgE-binding analysis of overlapping peptides bound to membranes. Sequential IgE epitopes can be screened by this strategy. However, the information about conformational epitopes, which are of great importance in highly resistant proteins such as nsLTPs, would be lost due to the own limitation of the technique. The inherent restrictions of this approach suggest that potentially relevant IgE-binding regions of the allergen studied, particularly conformational epitopes formed by sequentially discontinuous amino acid residues, cannot be detected (Aalberse, 2000; Christensen et al., 2008). The production of hypoallergenic forms has been used to analyze structural epitopes. However, this is a laborious strategy, because of the difficulty of selecting the residues to be mutated. New strategies have been developed in recent years to study and characterize regions with IgE-binding capacity. Phage display has shown itself to be a powerful tool for uncovering conformational mimic epitopes or mimotopes from random peptide phage libraries (Folgori et al., 1994; Ganglberger et al., 2000; Luzzago et al., 1993). Mimotope sequences represent a region of the allergen that can be recognized by IgE, and thus led to identify a structural B-cell epitope (Davies et al., 2000: Ganglberger et al., 2000; Jensen-Jarolim et al., 1998; Myers et al., 2000). Mimotopes can also be used to develop new immunotherapy strategies, for example, in the design of peptide vaccines or in specific treatments with hypoallergenic proteins (Jensen-Jarolim et al., 1998, 1999).

Neither sequential nor conformational IgE epitopes of Tri a 14 have been located. In contrast, different Pru p 3-epitopes have been characterized by several methods (Garcia-Casado et al, 2003; Pacios et al., 2008; Tordesillas et al., 2009). Thus, three sequential regions, Pru p 311-25. Pru p 3/1-45 and Pru p 371-80, and a complex conformational epitope (N35N36L37R39T40P42D43R44A46S76177P78Y79), which comprises in Pru p 331-45 and Pru p 371-80, have been defined. The aim of the present work was to characterize relevant lgE-binding regions of Tri a 14, and to compare them with the homologous regions in Pru $\mathrm{p} 3$.

\section{Methods}

\subsection{Patients and sera}

Patients with baker's asthma caused by wheat flour were recruited at the Servicios de Alergia of Hospital Universitario La Paz (Madrid, Spain) and Hospital Universitario Rio Hortega (Valladolid.
Spain). The criteria for selection were as follows: (1) a convincing clinical history of occupational asthma provoked by inhalation of wheat flour (Quirce et al., 2006): (2) a positive skin prick test (SPT) response to in-house wheat salt-soluble protein extract; (3) specific lgE level to wheat of greater than $0.35 \mathrm{kU} / \mathrm{L}$ as determined by the Pharmacia CAP System FElA (Phadia, Uppsala, Sweden). Considering that the major aim of the present work was to analyze common epitopes between Pru p 3 and Tri a 14, sera from 8 patients who covered the selection criteria, and showed specific IgE to both purified nsLTPs as measured by ELISA assay (see below), were further selected and used in this study.

As negative control to test the specify of the phage display, a pool of sera from atopic patients $(n=4)$ without plant food allergies and without specific IgE to nslTPs were selected.

Written informed consent was obtained from all patients and the study was approved by the corresponding ethics committees of both hospitals.

\subsection{ELISA assays}

An in-house wheat extract of salt-soluble proteins, as well as rTri a 14, were obtained according to Palacin et al. (2007, 2009), and $\mathrm{rPru} \mathrm{p} 3$ was produced and isolated following Diaz-Perales et al. (2003). Purified allergens were quantified by means of the commercial bicinchoninic acid test (Pierce, Cheshire, UK), and purity ascertained by a single band of the expected molecular size in SDSPAGE analysis and a single and expected (Diaz-Perales et al., 2000, 2003: Palacin et al., 2009) N-terminal amino acid sequence (10 residues).

Specific IgE to the wheat extract ( $15 \mu \mathrm{g} / \mathrm{mL}$ in solid phase) and purified rPru p 3 and rTri a $14(5 \mu \mathrm{g} / \mathrm{mL})$ were determined in each individual serum (1:5 dilution) from the 8 selected patients with baker's asthma by means of a previously described direct ELISA method (Diaz-Perales et al., 2000). Blocking solution (Sigma) without solid phase was used as negative control. Specific IgE levels greater than 0.1 OD units (mean [OD] $+3 \times$ S.D. to blocking) were considered positive. All tests were performed in triplicate.

The specificity of lgE-selected phage recognition was confirmed by ELISA assays. Plates, coated with a monoclonal antibody antiHuman IgE (ABR Affinity BioReagents, Rockford, USA) and blocked, were incubated with individual clones $(100 \mu \mathrm{g} / \mathrm{mL})$. After washing, a serum pool $(1: 5,50 \mu \mathrm{L})$ from the selected baker's asthma patients or a serum pool from atopic non-fruit allergic patients $(1: 5,50 \mu \mathrm{L})$ used as negative control was added. Binding was revealed with anti-M13-peroxidase-conjugated monoclonal antibody (1:1000 dilution; GE Healthcare Bioscience).

\subsection{Dot-blot analysis of solid phase-bound synthetic peptides}

Synthetic peptides (5-mer overlapping decapeptides) spanning the entire Pru p 3- or Tri a 14-sequence and covalently bound to a cellulose membrane (SPOTs) were obtained from JPT Peptide Technologies (Berlin, Germany). A SPOT membrane with two different rows, one with Tri a 14-peptides and another with Pru p 3-peptides, was incubated with blocking-PBS buffer (Sigma, Steinheim, Germany) for $3 \mathrm{~h}$ at $25^{\circ} \mathrm{C}$ and then overnight with a serum pool (1:5 dilution) from baker's asthma patients. The IgE-binding spots were subsequently revealed by ${ }^{125}$ [-labeled anti-human IgE (ALK-Abelló, Madrid, Spain) for $4 \mathrm{~h}$ at $25^{\circ} \mathrm{C}$, and autoradiography (5 days exposure at $-80^{\circ} \mathrm{C}$ ).

\subsection{Selection of phage-displayed IgE epitope-mimicking peptides}

This selection was carried out as previously described (Mittag et al., 2006). A 2-mL aliquot of a suspension of Tosyl-activated M280 Dynabeads (lnvitrogen Dynal, Oslo, Norway) was loaded with 
$100 \mu \mathrm{g}$ monoclonal mouse-anti-human IgE (ABR Affinity BioReagents) overnight. They were then washed with PBS $0.5 \%(\mathrm{w} / \mathrm{v}) \mathrm{BSA}$ and with PBS $0.1 \%$ BSA. The anti-lgE-coated beads were blocked with PBS $2 \%(w / v)$ skim milk. The serum pool from selected patients was diluted in PBS with $0.05 \%$ Tween $20,0.1 \%$ skim milk (dilution $1: 5$ ), and incubated with $200 \mu \mathrm{L}$ coated bead suspension at $4^{\circ} \mathrm{C}$ overnight. The total IgE of baker's asthma patients was retained, bound to the coated beads. After extensive washing, $100 \mu \mathrm{L}$ of them was used immediately for the first round of selection, while the remaining $100 \mu \mathrm{L}$ was retained for the second selection round.

\subsubsection{First selection round}

The IgE coated beads were incubated for $3 \mathrm{~h}$ with $2^{11}$ phages from a library of phages displaying linear random 12-mer peptides (PH.D.-12 Phage Display Peptide Library $2.7 \times 10^{9}$ clones; New England Biolabs, UK), and washed with dilution buffer to remove unbound phages. The phages still bound to the beads were amplified by direct infection of ER2738 Escherichia coli cells (provided with the phage library) following the manufacturer's instructions. Phage amplification was allowed overnight at $30^{\circ} \mathrm{C}$. Phages were purified by PEG-precipitation and titred.

\subsubsection{Second selection round}

The beads with immobilized IgE were incubated with $2^{11}$ amplified phages selected in the first round. The beads were then washed and aliquoted for specific elution with $500 \mu \mathrm{L}$ of $25 \mu \mathrm{g}$ protein $/ \mathrm{mL}$ of recombinant allergen (Tri a 14 and Pru p 3 ) in PBS with $0.1 \%$ (w/v) skim milk, One aliquot was eluted with one allergen, and centrifuged. The pellet was then eluted with the other allergen. Titres of eluted phages were determined. Single colonies were picked and isolated phage preparations were made and processed as described by the library manufacturer. Amino acid sequences of the displayed peptides were deduced from the DNA sequences obtained for each phage clone using M13 phage-specific primers

\subsection{Location of mimotopes on protein surfaces and calculation of electrostatic potentials}

Chain A of both X-ray structures of Pru p 3 (PDB code 2B5S, Pasquato et al., 2006) and Tri a 14 (PDB code 1BWO, Gincel et al., 1994) were used to obtain the solvent-excluded surface (SES). Residues of clones were identified on the surface of both nsLTPs by searching for connected regions after locating every individual residue area on the surface with Swiss-PDB Viewer (Pacios, 1994) (www.expasy.org/spdbv). Relative accessibilities were obtained also with Swiss-PDB Viewer and SES areas computed with Chimera 1.3 (Pacios, 2001). The electrostatic Poisson-Boltzmann(PB) potential was calculated with APBS 0.4 .0 (Wang et al., 2004), assigning AMBER99 atomic charges and radii including hydrogens added with PDB2PQR (Dolinsky et al., 2004). Fine (0.50- $\AA$ spacing) grids around the 1276 (Pru p 3) and 1313 (Tri a 14) resulting atoms were used to solve the nonlinear PB equation in sequential-focusing multigrid calculations for meshes of 97 points per dimension at $298.15 \mathrm{~K}$ with dielectric constants of 2 for proteins and 78.54 for water. Potential values are given in units of $k T$ per unit charge ( $k$, Boltzmann's constant; $T$, absolute temperature). PB potentials mapped onto protein surfaces, PB spatial isosurfaces and molecular graphics were obtained with PyMOL 1.1 (www.pymol.org).

\section{Results}

\subsection{IgE-recognition of sequential regions from Tri a 14 and Prup 3}

Tri a 14- and Pru p 3-derived decapeptides (5-mer overlapping) spanning the full amino acid sequences of each allergen were

\section{(A) Tri a 14 \\ Pru p 3

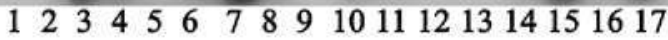



Fig. 1. (A) lgE immunodetection using a serum pool from patients with baker's asthma of SPOTs with synthetic decapeptides spanning the entire Tri a 14 or Pru p 3 amino acid sequence. (B) Alignment of the amino acid sequences of Tri a 14 and Pru $\mathrm{p} 3$ highlighting the positions of the main lgE-binding peptides in each allergen.

scanned with IgE from a serum pool of baker's asthma patients sensitized to both allergens (Fig. 1A). Spots corresponding to peptides 7 (positions 31-40), 11 (positions 51-60) and 14-15 (positions 66-80) from Tri a 14, as well as those to peptides 3 (positions 11-20), 7 (positions 31-40), 15 (positions 71-80) and 17 (positions 81-91) from Pru p 3, showed the strongest IgE-recognition (Fig. 1A and B). The sequential regions identified in Pru p 3 essentially correspond to sequential epitopes $1-3$ (residues 11-25,31-45 and $71-80$, respectively) previously described by Garcia-Casado et al. (2003).

These results indicate the presence of common (positions 31-40 and 71-80) and specific (positions 51-60 in Tri a 14 and 11-20 in Pru p 3) sequential IgE-binding regions in the wheat and peach nsLTP allergens.

\subsection{Identification of mimotopes of Tri a 14 and Pru $p 3$}

A phage display peptide library was incubated with $\lg E$ isolated from the baker's asthma serum pool. After two selection rounds, specific clones were eluted in two steps for both proteins (Fig. 2A). Firstly, specific clones were eluted with Tri a 14 (T1). Non-eluted phages were then incubated with Pru p 3, eluting Pru p 3-specificclones (P2). The same was done eluting first with Pru p 3 (P1), and afterwards with Tri a 14, thus selecting Tri a 14-specific-clones (T2). Clones from each elution were amplified overnight, the DNAinsertion of 10 clone/elution was sequenced and the corresponding amino acid sequences were deduced (Fig. 2B).

The specificity of the $\operatorname{lgE} /$ clone binding was further confirmed by means of ELISA assays using anti-human IgE/serum pool coated plates incubated with each selected clone. Only the results obtained with 5 clones/elution are shown in Fig. 3. Every clone was recognized by IgE from patients with baker's asthma. However, no significant activity was detected when IgE from atopic patients non-sensitized to LTPs was used, confirming the specificity of the selection method. Thus, the selected clones can be considered specific mimotopes of Pru p 3 or Tri a 14, respectively.

\subsection{Location of IgE epitopes on the structure of Pru $p 3$ and Tri a 14}

The selected clones of each elution were localized onto the surface of Pru p 3 and Tri a 14. Four consensus sequences (one per elution) were obtained selecting the residues which appeared more frequently in clones together with their localization on the surface of the corresponding allergen (Fig. 2B). The comparison of the consensus sequences of both elutions for the same protein ( $\mathrm{T} 1$ versus $\mathrm{T} 2$ and $\mathrm{P} 1$ versus $\mathrm{P} 2$ ) rendered essentially the same residues. For this reason, a final set of residues was defined for each allergen (Fig. 2C) based on the deduced amino acid sequences complemented by surface mapping of the corresponding residues. 
(A)



(B)



Consensus sequences:

$$
\begin{aligned}
& \begin{array}{|l|l|}
\hline \mathrm{T} 1: \mathrm{I}_{34} \mathrm{H}_{35} \mathrm{~N}_{36} \mathrm{R}_{39} \mathrm{~S}_{40} \mathrm{~S}_{42} \mathrm{D}_{43} \mathrm{P}_{70} \mathrm{I}_{77} \mathrm{P}_{78} \mathrm{P}_{79} \mathrm{~T}_{30} & \mathrm{P} 1: \mathrm{N}_{36} \mathrm{I}_{37} \mathrm{R}_{39} \mathrm{D}_{43} \mathrm{R}_{44} \mathrm{~V}_{75} \mathrm{~S}_{76} \mathrm{I}_{77} \mathrm{P}_{78} \mathrm{Y}_{79} \mathrm{~K}_{90} \\
\mathrm{~T} 2: \mathrm{I}_{34} \mathrm{H}_{35} \mathrm{~N}_{36} \mathrm{R}_{39} \mathrm{~S}_{40} \mathrm{E}_{63} \mathrm{P}_{70} \mathrm{I}_{77} \mathrm{P}_{78} \mathrm{Y}_{79} \mathrm{~T}_{80} \mathrm{~S}_{82} & \mathrm{P} 2: \mathrm{N}_{36} \mathrm{I}_{37} \mathrm{R}_{38} \mathrm{D}_{43} \mathrm{R}_{44} \mathrm{~V}_{75} \mathrm{~S}_{76} \mathrm{I}_{77} \mathrm{P}_{79} \mathrm{Y}_{79} \mathrm{~K}_{90} \\
\hline
\end{array} \\
& \text { MIMOTOPE: } \\
& \begin{array}{ll|ll}
\text { Tri a } 14: \mathrm{H}_{35} \mathrm{~N}_{38} \mathrm{R}_{39} \mathrm{~S}_{40} \mathrm{~S}_{42} \mathrm{D}_{43} \mathrm{G}_{74} \mathrm{~V}_{75} \mathrm{~L}_{77} \mathrm{P}_{78} \mathrm{Y}_{79} \mathrm{~T}_{80} & \text { Pru p 3: } \mathrm{H}_{35} \mathrm{~N}_{38} \mathrm{R}_{39} \mathrm{~T}_{40} \mathrm{D}_{43} \mathrm{R}_{48} \mathrm{G}_{74} \mathrm{~V}_{75} \mathrm{~S}_{76} \mathrm{I}_{77} \mathrm{P}_{78} \mathrm{Y}_{79} \\
\hline
\end{array}
\end{aligned}
$$

Fig. 2. (A) Strategy followed to isolate clones expressing mimotopes of Tri a 14 and Pru p 3. (B) Amino acid sequences of the selected clones for the different elutions. The consensus sequence of the different elutions is indicated below. Final consensus sequences for the potential mimotopes for each allergen are also shown.

Even, residues mapped onto Tri a 14 surface and those localized in Pru $\mathrm{p} 3$ overlapped. In fact, no specific IgE region was found in Tri a 14 with respect to Prup 3 . The final set of residues selected on both allergens (Figs. 2B and 4A) was located on two separate parts of the structure: near ends of helices 2 and 3 along with their connecting loop (part A) on one side, and the non-structured coil at the Cterminus (part B) on the other side. Given the overall similarity of these sets in Pru p 3 and Tri a 14, the specificity of the sensitization profile should be based on other features, such as molecular surface properties, which therefore, were explored.

Part A spans similar surface regions in both allergens. It covers nearly identical surface areas ( 388 and $400 \AA^{2}$ in Pru p 3 and Tri a 14, respectively) and shows a similar electrostatic positive behaviour revealed by both the PB potential mapped on the surface (Fig. 4B) and the PB isosurface extending outside the protein surface (Fig. 4C). Although part $B$ has six residues in both proteins, it covers a larger area in Tri a $14\left(390 \AA^{2}\right)$ than in Pru p $3\left(298 \AA^{2}\right)$ and shows a different electrostatic behaviour. While part B in Pru p 3 is neutral or weakly positive, in Tri a 14 it shows a negative nature. This feature is even more apparent in the large negative PB isosurface patches in Tri a 14 in a spatial region of the protein which is covered by a positive electrostatic field in Pru p 3.

\section{Discussion}

Members of the non-specific lipid transfer protein family, mainly peach Pru p 3, are known to be important allergens associated with plant food allergy, particularly in the Mediterranean region (Asero et al., 2009; Fernandez-Rivas et al., 2003; Salcedo et al., 2007; van Ree, 2002). These allergens are usually associated with oral sensitization, although there is considerable evidence of other routes by which they can sensitize (Garcia et al., 2004; Lauer et al., 2007; Lombardero et al., 2004; Salcedo et al., 2007; Zuidmeer and van Ree, 2007). Thus, wheat LTP, Tri a 14, has been recently characterized as a relevant inhalant allergen associated with baker's asthma (Palacin et al., 2007, 2009). An extensive cross-reactivity has been reported among allergenic nsLTPs from different plant foods, and between them and those from some pollen such as Artemisia and plane tree (Diaz-Perales et al., 2003; Lauer et al., 2007; Lombardero et al., 2004; Zuidmeer and van Ree, 2007). In this context, some baker's asthma patients sensitized to wheat Tri a 14 also recognize in vitro and in vivo peach Pru $\mathrm{p} 3$, whereas no cross-reactivity between both allergens is found in other patients with similar allergic disorder (Palacin et al., 2007, 2009). These experimental results suggest the presence of common, as well as specific IgE epitopes in Tri a 14 and Pru p 3. This scenario, together with the lack of information on Tri a 14 epitopes, led us to characterize such epitopes in the wheat allergen and to compare them with those located in Pru p 3. Three different and complementary strategies have been used: the analysis of IgE-binding capacity of 5 mer overlapping decapeptides bound to membrane, the characterization of mimotopes using a phage display of a 12-amino acid peptide library, and the analysis of surface electrostatic potential properties of both allergens.

Three relevant sequential regions of Tri a 14 have been identified by IgE immunodetection of synthetic decapeptides: Tri a $14_{31-40}$, 


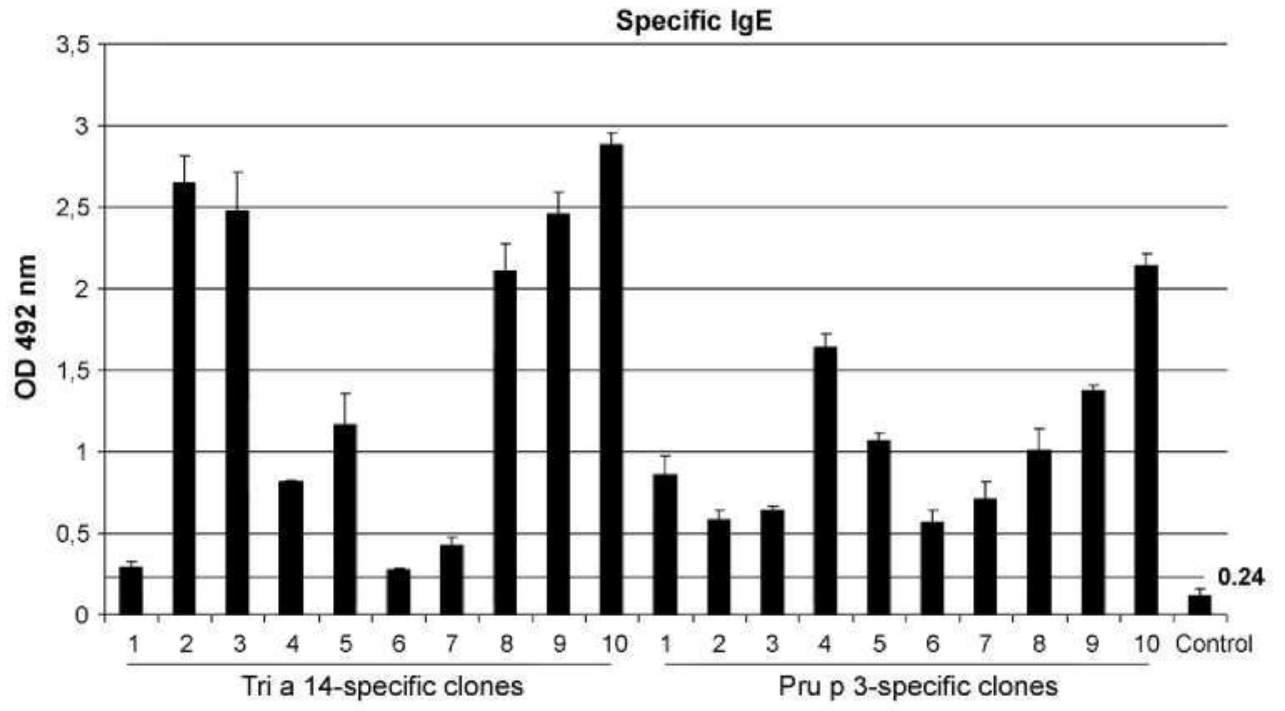

Fig. 3. lgE-binding to selected phage clones. ELSA assays were performed with monoclonal anti-human lgE in solid phase, a pool of sera from baker's asthma patients, and each selected clone. Means $(n=3)$ and S.D. (bars) are represented. Blocking solution was tested as negative cont rol, and cut-off value $(0,24$ OD units $=$ mean [0.12] $+3 \times$ S.D. [0.04] OD units of negative control) is indicated by a horizontal line.

Tri a $1451-60$, and Tria $14_{66-80}$. Comparison with the sequential IgEbinding regions here found in Pru p 3, namely Pru p 311-20, Pru p $3_{31-40}$ and Pru p $371-91$, which essentially overlapped with its $\operatorname{IgE}$ epitopes previously described (Garcia-Casado et al., 2003), indicate the presence of two common regions involved in IgE-binding (Tri a 1431-40/Pru p 331-40 and Tri a $14_{66-80}$ /Pru p $371-91$ ) that could mediate the cross-reactivity between both allergenic nsLTPs. In contrast, Tri a $14_{51-60}$ and Pru p $3_{11-20}$ would represent specific regions, which could partially account for the differential sensitization to the two allergens described in some patients.
The mapping of sequential epitopes has been complemented by the location of mimotopes (conformational epitopes) in both nsLTPs. Thus, H35 N36 R39 S40 D43 G74 V75 L77 P78 Y79 T80 was identified as the major mimotope of Tri a 14, which overlapped with Tri a $14_{31-40}$ and Tri a $14_{66-80}$, identified as common epitopes by synthetic peptides. In the same way, the Pru p 3-mimotope described in the present work, N36 L37 R39 T40 D43 R44 G74 V75 S76 177 P78 Y79, included the sequential epitopes Pru p 3 $31-40$ and Pru p 371-91, and is almost identical to that previously characterized (Pacios et al., 2008). It should be emphasized that the identified
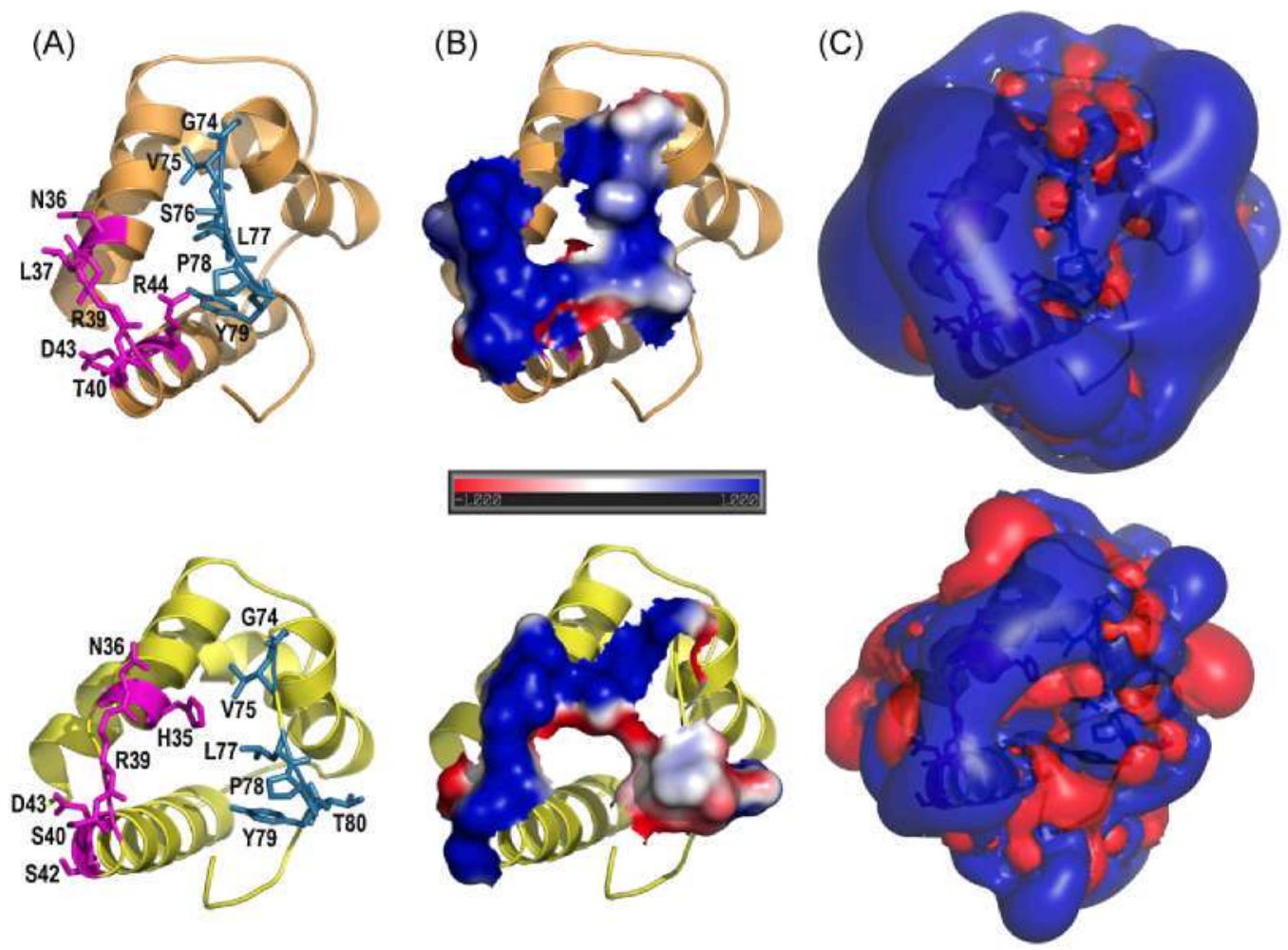

Fig. 4. Amino acids in Pru p 3 (upper row) and Tri a 14 (lower row) mimotopes. (A) Ribbon diagrams showing side chains of residues in the region of the loop between helices 2 and 3 in magenta, and residues in the non-structured coil at the C-terminus in blue. (B) Surfaces of residues in A with the PB electrostatic potential mapped onto the surface. (C) PB electrostatic potential isosurfaces -1 (red) and +1 (blue) in the space outside the protein surface. (A-C) Plotted at the same spatial orientation. 
mimotopes comprise two out of the three sequential lgE-binding regions defined in each allergen. The correspondence of the results obtained by two strategies (synthetic peptides bound to membrane and phage display) is evidence of their complementarity. However, the residues contained in sequential epitopes Tri a $14_{51-60}$ and Pru p 311-20, were not identified in the selected clones by phage display. This might be explained by their location on the protein 3D-structure that shows low relative accessibilities for the majority of residues in these sequences. This highlights the difficulty of fulfilling their role in sensitization, taking into consideration the high stability of the nsLTP-folding. However, the role of Tri a $14_{51-60}$ in baker's asthma cannot be ruled out.

The alignment of Tri a 14- and Pru p 3-mimotopes resulted in the presence of a main core that can be involved in cross-reactivity: N36 R39 T/S40 S42 D43 G74 V75 ]/L77 P78 Y79. These core residues. localized in two distant regions in the amino acid sequence, were close in the 3D-structure and gave rise to two differentiated surface regions with distinct electrostatic features. Electrostatic potentials of part A, Tri a $14_{31-40} /$ Pru p $331-45$, show similar positive behaviour and comparable surface areas. On the contrary, part $\mathrm{B}_{+}$ Tri a 1465-80/Pru p 371-80, have markedly different characteristics. Although the residues were rather similar, Tri a 14 exhibited significant negative potential and larger areas than Pru p 3, which shows besides a neutral or positive potential. This distinct electrostatic nature could bring about differences in the recognition of the two allergens by molecular properties of the regions involved. Hence, the specific residues would not be as important as the determinant of sensitization. However, further experimental evidence is required to confirm this hypothesis.

In summary, this work identifies most of the IgE epitopes of Tri a 14 as corresponding to those identified here and also previously described in Pru p 3. The conservation of the residues in both allergens (and in other allergenic members) of the nsLTP family (Salcedo et al., 2007) may explain the cross-reactions among allergens of this protein group. Moreover, epitopes involved in food allergies appear to be the same as those recognized by other types of sensitization, such as that occurring in the respiratory tract. Hence, the Pru p 3-mimotope jdentified using lgE from baker's asthma patients (inhalation allergy) is almost the same as that previously described when using sera of peach-allergic patients (food allergy). This finding could be of relevance to the design of new hypoallergenic mutants for use in alternative immunotherapy strategies. However, specific sequential epitopes described by synthetic peptides (Tri a 1451-60 and Pru p $3_{11-20}$ ) and electrostatic potential differences of conformational regions involved in lgE-binding can explain the specific sensitization to both allergens.

The obtained results in this work confirm the power of mimotope identification in the study of conformational epitopes as an alternative way of producing hypoallergenic proteins. The technique could be of particular importance in the study of food allergens, given that nsLTPs probably involve mainly conformational epitopes. The wider use of this technique would undoubtedly facilitate the characterization of IgE epitopes in different allergens (Partidos and Steward, 2002; Riemer et al., 2004; Sharav et al., 2007).

\section{References}

Aalberse, R,C., 2000. Structural biology of allergens. J. Allergy Clim, Immunol. 106. 228-238.

Armentia, A., Sanchez-Monge, R., Gomez, L., Barber, D., Salcedo, G., 1993. In vivo allergenic activities of eleven putified members of a major allergen tamily from wheat and barley flour. Clin. Exp. Allergy 23, 410-415.

Asero, R., Antonicelli, L., Arena, A., Bommaríto, L., Canıso, B., Crivellaro, M., De Carli, M., Della Torre, E., Della Torte, F., Hetfler, E., Lodi Rizzini, F., Longo, R., Manzotti, G. Marcotulli, M. Melchiorre, A. Minale, P. Morandi, P. Moreni, B. Moschella, A. Murzilli, F., Nebiolo, F. Poppa, M., Randazzo, S., Rossi, G., Senna, G.E., 2009. Epide MAAITO: teatures of tood allergy in Italian adults attendingalletgy clinics: a multi-centre study. Clin. Exp. Allergy 39, 547-555.
Barber, D., de la Torre, F., Feo, F., Florido, F., Guardia, P., Moreno, C., Ouiralte, I. Lombardero, M., Villalba, M., Salcedo, $G_{\text {. }}$ Rodriguez, R., 2008, Understanding pat ient sensitization protiles in complex pollen areas: a molecular epidemiological study. Allergy $63,1550-1558$.

Btant, A., 2007. Baker's ast lmma. Curr. Opin. Allergy Clin. Immunol. 7, 152-155.

Christensen, L.H., Holm, J., Lund, G., Riise, E., Lund, K., 2008. Several distinct properties of the lgE repertoire determine effector cell degranulation in response to allergen challenge. J. Alletgy Clin, Immunol. 122, 298-304.

Davies, J.M., O'Hehir, R.E., Suphioglu, C., 2000. Use of phage display technology to imvestigate allergen-antibody interactions. J. Allergy Clin. Immunol. 105. 1085-1092.

Diaz-Perales, A., Lombardero, M., Sanchez-Monge, R., Garcia-Selles, F.J., Pernas, M., Ferilandez-Rivas, M., Barber, D., Salcedo, G., 2000. Lipid-transfer proteins as potential plant panallergens: cross-reactivity among proteins of Artemisia pollen, Castanea nut and Rosaceae fruits, with different IgE-binding capacities. Cliii. Exp. Allergy 30, 1403-1410.

Diaz-Perales, A., Sanz, M.L., Garcia-Casado, G., Sanchez-Monge, R., Garcia-Selles, F.J., Lombardero, M. Polo, F. Gamboa, P.M. Barber, D. Salcedo, G. 2003 Recombinaut Pou $\mathrm{p} 3$ and natural Pru p 3. a major peach alleryen, show equivalent immunologic reactivity: a new tool for the diagnosis of fnit allergy. J. Allergy Clin. Immunol. 111, 628-633.

Dolinsky. T.J., Nielsen, J.E., McCammon, J.A., Baker, N.A., 2004. PDB2PQR: an automated pipeline tor the setup of Poisson-Boltzmann electrostat ics calculations. Nucleic Acids Res, 32, W665-W667.

Fernandez-Rivas, M., Gonzalez-Mancebo, E., Rodriguez-Perez, R., Benito, C., SanchezMonge, R., Salcedo, G., Alonso, M.D., Rosado, A, Tejedor, M.A., Vila, C., Casas, M.L., 2003. Clinically relevant peach allergy is related to peach lipid transfer protein, Pru p 3, in the Spanish population. J. Allergy Clín. Immunol. 112, $789-795$

Folgori, A., Tafi, R., Meola, A., Felici, F., Galfre, G., Cortese, R., Monaci, P., Nicosì, A. 1994. A general strategy to identify mimotopes of pathological antigens using only random peptide libraries and liuman seta. EMBO J. 13. $2236-2243$.

Ganglberger, E, Grunberger, K., Sponer, B., Radauer, C., Breiteneder, H., BoltzNitulescu, C., Scheiner, O., Jensen-Jarolim, E., 2000. Allergen mimotopes for 3-dimensional epitope search and induction of ant ibodies inhibiting human IgE. FASEB J. 14, 2177-2184.

Garcia-Casado, G., Pacios, LF. Diaz-Perales, A Sanchez-Monge, R. Lombardero, M. Garcia-Selles, F.t., Polo, F., Barbet, D., Salcedo, G., 2003. Identification of IgEbinding epitopes of the major peach allergen Pru p 3. J. Allergy Clin. Immunol. 112, 599-605.

Garcia, B.E, Lombardero, M., Echechipia, S., Olaguibel, J.M., Diaz-Perales, A, SanchezMonge, R., Barber, D., Salcedo, G., Tabar, A.l., 2004. Respiratory allergy to peach leaves and lipid-transter proteins. Clin. Exp. Allengy 34, 291-295.

Gincel, E, Simorre, J.P., Caille, A., Mation, D., Ptak, M., Vovelle, F., 1994. Threedimensional structure in solution of a wheat lipid-transfer protein from multidimens ional 1H-NMR data. A new tolding for lipid cartiers. Eut. J. Biochem. $226,413-422$.

Jacobs, J.H., Meijster, T., Meijer, E., Suarthana, E., Heederik, D., 2008. Wheat allergen exposure and the prevalence of work-related sensitization and allergy in bakety workers. Allergy 63, 1597-1604.

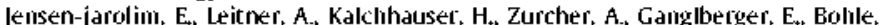
B., Scheinet; O. Boltz-nitulescu. G. Breiteneder, H. 1998. Peptide mimotopes displayed by phage inhibit antibody binding to Bet $v 1$, the major bich pollen allergen, and induce specific lgG tesponse in mice. FASEB J. 12, $1635-1642$.

Jensen-Jarolim, E., Wiedermann, U., Ganglberger, E., Zurcher, A., Stadler, B.M., Boltz-

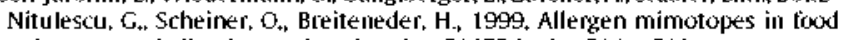
enhance type I allergic reactions in mice. FASEB J. 13, 1586-1592.

Lauer, I., Miguel-Moncin, M.S., Abel, T, Foetisch, K., Hart2, G, Fottunato, D, CisteroBahima, A., Vieths, S., Scheurer, S, 2007 Identification of a plane pollen lipid transfer protein (Pla a 3 ) and its immunological relation to the peach lipidtranster protein, Pru p 3. Clin. Exp. Allergy 37, 261-269.

Lombardero, M., Garcia-Selles, F.J., Polo, F., Jimeno, L., Chamorro, M.J., Garcia-Casado, G., Sanchez-Monge, R., Diaz-Perales, A, Salcedo, G., Barber, D., 2004, Prevalence of sensitization to Altemisia allergens Art $v 1$, Art $v 3$ and Art $v 60 \mathrm{kDa}$ C Cossreactivity among Ant $\vee 3$ and other relevant lipid-transfer prote in allergens. Clin. Exp. Allergy 34, 1415-1421.

Luzzago, A., Felici, F., Tramontano, A., Pessi, A., Cortese, R., 1993. Mimicking of discontinuous epitopes by phage-displayed peptides. I. Epitope mapping of liuman $\mathrm{H}$ ferritin using a phage library of constrained peptides. Gene 128, 5157.

Mittag, D., Batori, V., Neudecker, P., Wiclıe, R., Friis, E.P., Ballmer-Weber, B.K., Vietlis, $S_{*}$. Rogrgen, E. L, 2006. A novel approach for investigation of specific and crossreactive IgE epitopes on Bet $v 1$ and homologous food allergens in individual pat ients. Mol. Immunol. 43, 268-278.

Myers, M.A., Davies, J.M., Tong, J.C., Whisstock, J., Scealy, M., Mackay, I.R., Rowley. M.J. 2000. Contormational epitopes on the diabetes autoantigen GAD65 identified by peptide phage display and moleculat modeling. J. Immunol. 165. 3830-3838.

Pacios, L.F., 1994, Arvomolfcontour: molecular surface areas and volumes on personal computers. Comput. Chem. 18, 377-385.

Pacios, L.F., 2001. Distinct molecular surfaces and hydrophobicity of amino acid residues in proteins. J. Chem. Int. Comput. Sci, 41, 1427-1435.

Pacios, L.F., Tordesillas, L., Cuesta-Herranz, J, Compes, E., Sanchez-Monge, R., Palacin. A.r Salcedo, G., Diaz-Perales, A., 2008. Mimotope mapping as a complementary 
strategy to define allergen lgE-epitopes: peach Pu p 3 allergen as a model. Mol. Immunol, 45, 2269-2276.

Palacin, A, Quirce, S. Armentia, A., Fernandez-Nieto, M., Pacios, L.F., Asensio, T. Sastre, J., Diaz-Perales, A., Salcedo, G., 2007. Wheat lipid transfer protein is a major allergen associated with baket's astlıma, J. Allergy Clin. Immunol, 120 $1132-1138$.

Palacin, A., Varela, J., Quirce, S., del Pozo, V., Tordesillas, L., Barranco, P., FernandezNieto, M., Sastle, J.. Diaz-Perales, A., Salcedo, G., 2009. Recombinant lipidt ransfe protein Tri a 14: a novel heat and proteolytic resist ant tool for the diagnosis of baket's asthma, Clin Exp Alleryy. 39, 1267-1276.

Partidos, C.D., Steward, M.W., 2002. Mimotopes of viral antigens and biologically important molecules as candidate vaccines and potential immunotherapeutics. Comb. Clem. High Tliroughput Screetl 5, 15-27.

Pasquato, N. Berni, R. Folli, C Folloni, S Cianci, M. Pantano, S., Helliwell, J.R., Zanotti, G., 2006. Crystal structure of peach Pru p 3, the prototypic member of the family of plant non-specific lipid tianstet protein pan-alletgens. J. Mol, Biol. 356. $684-694$.

Pastorello, E.A., Farioli, L., Conti, A, Pravettoni, V., Bonomi, S., lametti, S., Fortunato, D. Scibilia, J Bindslev-Jensen, C, Ballmer-Weber, B, Robino, A.M. Otolani, C. 2007. Wheat IgE-mediated food allergy in European patients: alpha-amylase inhibitors, lipid transter ptoteins and low-molecular-weiglit glutemins. Aller genic molecules recognized by double-blind, placebo-controlled food challenge Int. Archi, Allengy Immunol, 144, 10-22.

Quitce, S., Fernandez-Nieto, M., Escudero, C., Cuesta, J., de Las Heras, M., Sastre, J. 2006. Bronchial responsiveness to bakery-derived allergens is strongly dependent on specitic skin sensitivity. Allergy 61, 1202-1208.
Riemer, A Scheiner, O Jensen-Jarolim, E 2004 Allergen mimotopes. Methods 32 321-327.

Salcedo, G., Sanchez-Monge, R, Barber, D., Diaz-Perales, A., 2007. Plant non-specific lipid transfer proteins: an interface between plant defence and human allergy. Biochim. Biophys. Acta 1771, 781-791.

Sharav, T., Wiesmuller, K.H., Walden, P., 2007. Mimotope vaccines for cancer immunotherapy. Vaccine 25,3032-3037.

Tatham, A.S., Shewry, P.R., 2008. Allergens to wheat and related ceteals. Clin. Exp. Allergy $38,1712-1726$

Tordesillas, L, Cuesta-Herranz, J. Gonzalez-Munoz, M., Pacios, L.F., Compes, E. Garcia-Cartasco, B., Sanchez-Monge, R, Salcedo, G., Diaz-Perales, A. 2009. Tcell epitopes of the major peach allergen, Pru p 3 : identification and differential T-cell response of peach-allergic and non-allergic subjects. Mol, Immunol. 46. $722-728$.

van Ree, R., 2002. Clinical importance of non-5pecific lipid transfer proteins as food allergens. Biochem. Soc. Trans. 30, 910-913.

Wang, J., Breslin, M.J., Coleman, P.J., Duggan, M.E., Hunt, C.A., Hutchinson, J.H., Leu, C.T. Rodan, S.B., Rodan, G.A., Duong le, T. Hattman, G.D., 2004. Non-peptid alpha beta 3 antagonists. Part 7: 3-substituted tetrahydro-naphtliyridime derivatives. Bioorg. Med. Chem. Lett. 14, 1049-1052.

Zuidmeer, $L$, van Ree, $R, 2007$. Lipid transter protein allergy: primary food allergy or pollenffood syndrome in some cases. Curr. Opin. Allergy Clin. Immunol. 7 $269-273$ 